\title{
Effect of Atmospheric Pressure on Performance of AEA and Air Entraining Concrete
}

\author{
Yan Shi $\mathbb{D}^{1},{ }^{1}$ Huaquan Yang, ${ }^{1}$ Shihua Zhou, ${ }^{1}$ Aiguo Wang, ${ }^{2}$ and Xingdong Lv $\left({ }^{1}\right.$ \\ ${ }^{1}$ Changjiang River Scientific Research Institute of Changjiang Water Resources Commission, Wuhan 430010, China \\ ${ }^{2}$ Anhui Key Laboratory of Advanced Building Materials, Anhui Jianzhu University, Hefei 230022, China \\ Correspondence should be addressed to Yan Shi; shiyan@mail.crsri.cn
}

Received 7 November 2017; Accepted 31 January 2018; Published 21 March 2018

Academic Editor: Claudio Pettinari

Copyright (C) 2018 Yan Shi et al. This is an open access article distributed under the Creative Commons Attribution License, which permits unrestricted use, distribution, and reproduction in any medium, provided the original work is properly cited.

The effect of atmospheric pressure on performance of air entraining agent (AEA) and air entraining concrete was studied in Tibet and Hubei, China. The result shows that the reduced atmospheric pressure increased surface tension and lowered foaming property of solution. The AEA with excellent foaming ability and stability is preferred in low atmospheric pressure. The freezethaw deterioration process of hardened pastes is relatively faster under low atmospheric pressure. The effect of air pressure on concrete frost resistance performance is more sensitive than the mechanical property. The bigger pores and poor uniformity of internal pore size distribution led to the deterioration of concrete macroscopic properties. Therefore, the AEA varieties should be preferred, the dosage of AEA should be increased, and pore structure of pastes should be optimized to ensure the durability of concrete frost resistance for construction in low-pressure areas.

\section{Introduction}

The altitude of China's Tibet region is higher than $3000 \mathrm{~m}$. The significant climatic environment of high-altitude area is low pressure, large temperature difference between day and night, dry and windy due to high and complex terrain, highaltitude atmospheric circulation, and solar and other strong radiation along with various other factors. In plateau climate conditions, air entraining concrete is used in hydropower, transportation, and civil engineering projects to resist the frequent freeze-thaw cycle to avoid freezing and other induced disease, thereby ensuring the safe operation of the building [1].

The AEA can introduce a large number of homogeneously distributed air micropores and, consequently, improve the mixing workability, antipermeability of concrete performance, and frost resistance $[2,3]$. The factors of ambient temperature, humidity, and air pressure affect the air entraining concrete performance besides the factors of raw materials, proportion of mixture, and construction method. The mechanism of atmospheric pressure affects relatively the concrete performance. Therefore, the corresponding test could not be easily carried out, and the relevant study is less reported. Mielenz et al. suggested that existing pressure gradient between the big bubbles and the small bubbles makes the transfer of air possible between the bubbles. The transfer of air leads to change in the volume of air in pastes over the period of time [4]. Ley et al. proposed that the diameter of bubbles becomes smaller or even breaks up [5]. This changes the pore volume and distribution in fresh concrete by increasing the pressure around the pores. At the same time, the liquid behavior of different AEAs is different. According to Zhu et al. [6], the air content of the concrete shows decreasing tendency with the decreasing atmosphere pressure. $\mathrm{Li}$ and $\mathrm{Fu}$ suggested that the air content of concrete shows linear decrease with the decreasing atmosphere pressure. The higher the initial air content, the greater the decreasing rate of the air content with the ambient air pressure is found. The greater the slump of concrete is, the stronger the ability to resist reduction in the air content due to lower air pressure is [7].

Under different atmospheric pressures in Chinese Tibet (below $70.0 \mathrm{kPa}$ ) and Hubei (about $101.1 \mathrm{kPa}$ ), the effect of atmospheric pressure on the surface tension and air entraining performance of AEA is studied by AEA quality test. The effect of atmospheric pressure on macroscopic properties and micropore structure is studied by testing the air content of fresh 
TABle 1: Chemical composition of cement and fly ash by weight (\%).

\begin{tabular}{lccccccccc}
\hline Compositions & $\mathrm{CaO}$ & $\mathrm{SiO}_{2}$ & $\mathrm{Al}_{2} \mathrm{O}_{3}$ & $\mathrm{Fe}_{2} \mathrm{O}_{3}$ & $\mathrm{MgO}$ & $\mathrm{K}_{2} \mathrm{O}$ & $\mathrm{Na}_{2} \mathrm{O}$ & $\mathrm{SO}_{3}$ & $\mathrm{Loss}$ \\
\hline Cement & 62.05 & 20.71 & 4.44 & 5.12 & 4.12 & 0.28 & 0.11 & 2.23 & 0.9 \\
Fly ash & 3.27 & 46.19 & 36.95 & 4.43 & 0.38 & 1.01 & 0.38 & 0.38 & 3.58 \\
\hline
\end{tabular}

TABLe 2: Physical properties of cement.

\begin{tabular}{|c|c|c|c|c|c|c|}
\hline \multirow{2}{*}{$\begin{array}{l}\text { Specific area } \\
\left(\mathrm{m}^{2} \cdot \mathrm{kg}^{-1}\right)\end{array}$} & \multirow{2}{*}{$\begin{array}{c}\text { Fitness } \\
(\%)\end{array}$} & \multirow{2}{*}{$\begin{array}{l}\text { Density } \\
\left(\mathrm{g} \cdot \mathrm{cm}^{-3}\right)\end{array}$} & \multirow{2}{*}{$\begin{array}{l}\text { Water requirement of normal consistency } \\
(\%)\end{array}$} & \multicolumn{3}{|c|}{ Setting time (minimum) } \\
\hline & & & & Stability & $\begin{array}{l}\text { Initial } \\
\text { setting }\end{array}$ & $\begin{array}{c}\text { Final } \\
\text { setting }\end{array}$ \\
\hline 390 & 3.7 & 3.21 & 23.2 & Qualified & 185 & 270 \\
\hline
\end{tabular}

TABLE 3: Physical properties of fly ash.

\begin{tabular}{lccc}
\hline & & & \multicolumn{2}{c}{$\begin{array}{c}\text { Percentage of compressive } \\
\text { strength* }(\%)\end{array}$} & \multicolumn{2}{c}{$\begin{array}{c}\text { Density }\left(\mathrm{g} \cdot \mathrm{cm}^{-3}\right) \\
\text { Fitness (\%) }\end{array}$} & & 7 days & 61.3 \\
\hline 7.9 & 98 & 2.3 & 72.3 \\
\hline
\end{tabular}

*Strength ratio between test mortar with fly ash ( $30 \%$ by mass of cement) and base mortar at 28 days of age.

TABLE 4: Mix proportions of concrete.

\begin{tabular}{lcccccc}
\hline $\begin{array}{l}\text { Water } \\
\left(\mathrm{kg} \cdot \mathrm{m}^{-3}\right)\end{array}$ & $\begin{array}{c}\text { Cement } \\
\left(\mathrm{kg} \cdot \mathrm{m}^{-3}\right)\end{array}$ & $\begin{array}{c}\text { Fly ash } \\
\left(\mathrm{kg} \cdot \mathrm{m}^{-3}\right)\end{array}$ & $\begin{array}{c}\text { Fine aggregate } \\
\left(\mathrm{kg} \cdot \mathrm{m}^{-3}\right)\end{array}$ & $\begin{array}{c}\text { Coarse aggregate } \\
\left(\mathrm{kg} \cdot \mathrm{m}^{-3}\right)\end{array}$ & $\begin{array}{c}\text { Superplasticizer } \\
(\%)\end{array}$ & AEA A (\%) \\
\hline 124 & 174 & 74 & 675 & 1326 & 0.8 \\
\hline
\end{tabular}

concrete, the compressive strength of concrete, CT meso-map, and the mercury injection of freeze-thaw specimens. The aim of this study is to optimize the AEA varieties, improve the durability of concrete, improve the quality of engineering structure, and provide technical reference for prolonging the engineering life.

\section{Experimental}

2.1. Raw Materials and Concrete Mix. Moderate heat Portland cement PM 42.5 (Chinese standard GB175-2007), F class II level fly ash (Chinese standard DL/T 5055-2007), granite aggregates, and chemical admixtures are used in this study. Chemical compositions of cement and fly ash are shown in Table 1. Physical properties of cement and fly ash are shown in Tables 2 and 3, respectively.

The chemical admixtures include superplasticizer and liquid AEA A and AEA B. The raw materials' quality satisfied all the corresponding Chinese technical specifications. The maximum particle size of aggregates is found to be $40 \mathrm{~mm}$. The slump of fresh concrete is found between $50 \mathrm{~mm}$ and $70 \mathrm{~mm}$. The mix proportions of concrete are shown in Table 4.

\subsection{Experimental Methods}

2.2.1. Solution Characteristics of AEA. The surface tension of the same batch of liquid AEA was tested by the platinum ring surface tension apparatus in three different places (Hubei Wuhan, 101.1 kPa, Tibet Shannan, $65.9 \mathrm{kPa}$, and Tibet Naqu, $57.2 \mathrm{kPa}$ ). The foaming capacity and foam stability of the AEA were tested by the shaking method. Shake $10 \mathrm{ml}$ of $1 \%$ solution for 3 minutes, record the volume of foam, and observe the foam morphology from 0 minutes to 3 minutes.

2.2.2. Macroscopic Properties of Concrete. The concrete is mixed and formed in Wuhan and Tibet indoor test labs, respectively. The condition of the mixing room is kept at temperature $20 \pm 5^{\circ} \mathrm{C}$ and relative humidity $60 \% \pm 5 \%$ according to the China Power Industry Standard DL 5150. The concrete air content is tested using a concrete air content measuring instrument from Sanyo, Japan. The concrete samples are tested for their compressive strength and frost resistance property using the specimens of $150 \mathrm{~mm} \times 150 \mathrm{~mm} \times 150 \mathrm{~mm}$ and $100 \mathrm{~mm} \times 100 \mathrm{~mm} \times 400 \mathrm{~mm}$ prisms, respectively.

2.2.3. Microscopic Properties of Concrete. The microdistribution of the cross section of the specimen before and after freeze-thaw cycles is measured by a CT tester. The internal paste pore structure of frozen-thaw cycle specimens is tested by the mercury injection method with the pore size determination range of $3 \mathrm{~nm} \sim 1000 \mu \mathrm{m}$.

\section{Results and Discussion}

3.1. Solution Characteristics of AEA. The quality characteristics and effect of AEA are essential to ensure the frost resistance durability of concrete under low atmospheric pressure. The AEA is usually a surfactant which can significantly reduce the surface tension and interfacial energy of 
TABLE 5: Surface tension and foaming property of AEA under different air pressures.

\begin{tabular}{|c|c|c|c|c|c|c|c|c|}
\hline \multirow[b]{2}{*}{ Sample } & \multirow{2}{*}{$\begin{array}{l}\text { Atmospheric } \\
\text { pressure }(\mathrm{kPa})\end{array}$} & \multicolumn{2}{|c|}{ Surface tension } & \multicolumn{5}{|c|}{ Foaming ability } \\
\hline & & $\begin{array}{l}\text { Test value } \\
\left(\mathrm{mN} \cdot \mathrm{m}^{-1}\right)\end{array}$ & $\begin{array}{l}\text { Growth } \\
\text { rate }(\%)\end{array}$ & $\begin{array}{c}\text { Foaming } \\
\text { capacity }(\mathrm{ml})\end{array}$ & $\begin{array}{l}\text { Foaming capacity at } \\
3 \mathrm{~min}(\mathrm{ml})\end{array}$ & $\begin{array}{c}\text { Foam } \\
\text { stability (\%) }\end{array}$ & $\begin{array}{l}\text { Defoaming } \\
\text { time (min) }\end{array}$ & $\begin{array}{l}\text { Bubble } \\
\text { shape }\end{array}$ \\
\hline \multirow[t]{3}{*}{ AEA A } & 101.1 & 29.4 & 100 & Full & Full & 100 & $\geq 72 \mathrm{~h}$ & $\begin{array}{c}\text { Small, } \\
\text { much even }\end{array}$ \\
\hline & 65.9 & 32.9 & 112 & Full & Full & 100 & $\geq 48 \mathrm{~h}$ & Big, little, \\
\hline & 57.2 & 34.6 & 118 & 50 & 49 & 98 & $\geq 48 \mathrm{~h}$ & sparse \\
\hline \multirow[t]{3}{*}{ AEA B } & 101.1 & 31.9 & 100 & 38 & 36 & 95 & $\geq 36 \mathrm{~h}$ & $\begin{array}{c}\text { Moderate, } \\
\text { even }\end{array}$ \\
\hline & 65.9 & 34.2 & 107 & 32 & 30 & 94 & $\geq 24 \mathrm{~h}$ & Big, little, \\
\hline & 57.2 & 36.3 & 114 & 29 & 26 & 90 & $\geq 24 \mathrm{~h}$ & sparse \\
\hline
\end{tabular}

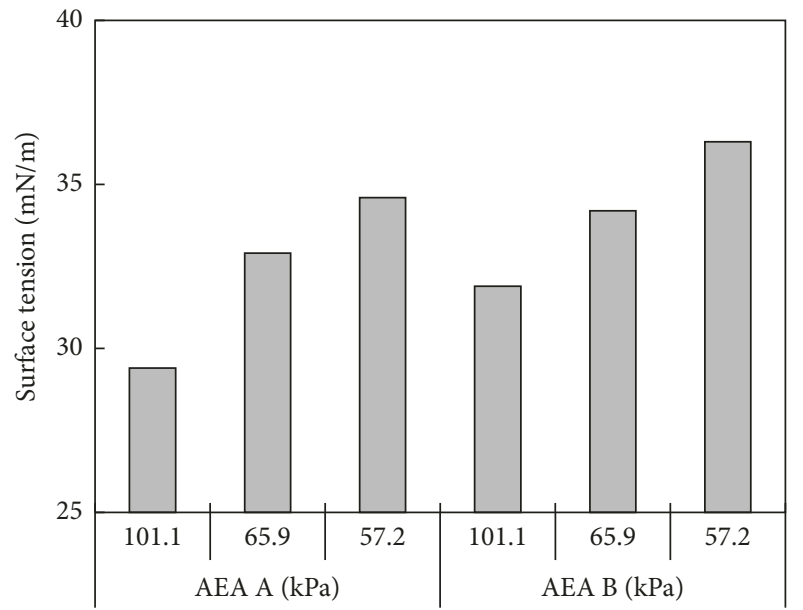

Figure 1: Surface tension histogram of AEA under different air pressures.

water. As a result, small and uniform, mostly under $200 \mu \mathrm{m}$ in diameter large amounts of bubbles are produced during mixing. The AEA molecules are adsorbed on the surface of the bubbles to form a firmer liquid film, making the bubbles stable and not easily broken $[2,5]$.

In order to optimize the AEA suitable for high-altitude area, the surface tension and foam capacity of AEA under different air pressures are compared. As shown in Table 5 and Figure 1, atmospheric pressure decreases from $101.1 \mathrm{kPa}$ to $57.2 \mathrm{kPa}$, and the surface tension with two kinds of AEA solution increases. The growth rates are $118 \%$ and $114 \%$, the AEA foaming ability decreases, and foam becomes large and thin, which reduces defoaming time. Thus foaming capacity and foam stability of different AEAs are different. The strength of the single molecular membrane on the airwater surface directly determines the stability of the bubbles [8]. With excellent bubble stability, air entraining agent can introduce the lower loss and the higher strength bubbles in concrete. The distribution of bubbles is more small, stable, and reasonable which can enhance the frost resistance durability of the concrete. In contrast, at lower atmospheric pressure, AEA A has stronger foaming ability, longer defoaming time, and better foam stability, which is more suitable for air entraining concrete used in highaltitude environment.

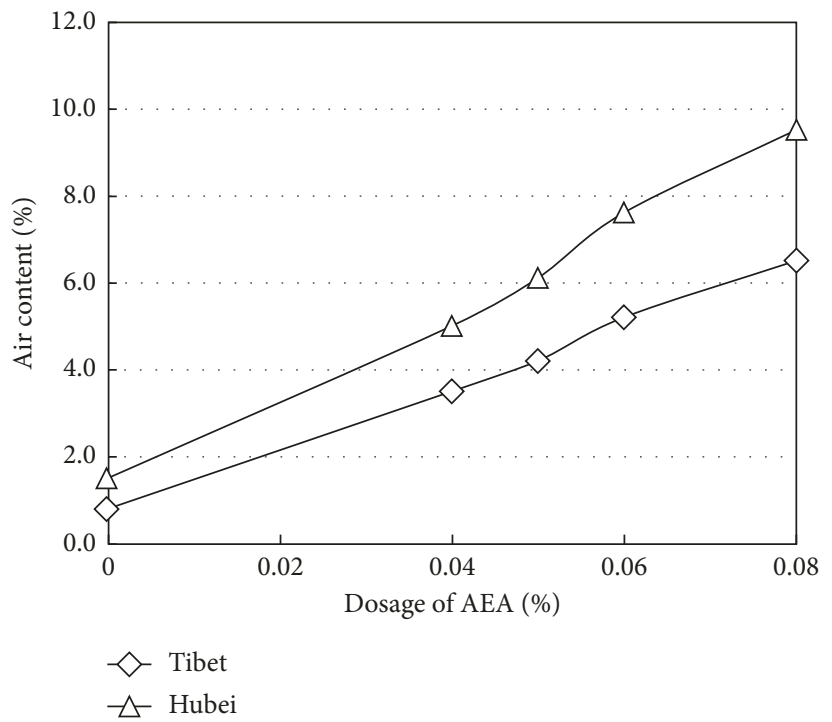

Figure 2: The relationship between dosage of AEA and concrete air content under different atmospheric pressures.

3.2. Air Content of Fresh Concrete. The relationship between dosage of AEA and air content of fresh concrete under different atmospheric pressures is shown in Figure 2. The result shows that the air content of fresh concrete mixing in Tibet is lower than that of concrete mixing in Wuhan with the same raw materials, mix proportions, and construction method. The percentage of reduction rate was 30\% 47\%; the more the dosage of AEA is, the more the percentage is.

The relationship between atmospheric pressure and altitude is characterized by the following equation [9]:

$$
P=P_{0} \times\left(1-\frac{H}{44330}\right) 5.225,
$$

where $P_{0}(\mathrm{kPa})$ is the standard atmospheric pressure of $101.3 \mathrm{kPa}$ and $P(\mathrm{kPa})$ is the air pressure value for altitude of $H(\mathrm{~m})$. Therefore, for the altitudes of $23 \mathrm{~m}$ (Wuhan and Hubei), $3500 \mathrm{~m}$ (Shannan and Tibet), and $4600 \mathrm{~m}$ (Naqu and Tibet), the corresponding air pressures are $101.1 \mathrm{kPa}$, $65.9 \mathrm{kPa}$, and $57.2 \mathrm{kPa}$, respectively. The air pressure in the Tibet region is only equivalent to 0.7 of standard atmospheric pressure. It could be seen that the difference of ambient air pressures affected the air content of fresh concrete. The result shows that lower ambient air pressure is 
TABLE 6: Compressive strength of concrete formed under different air pressures.

\begin{tabular}{|c|c|c|c|c|c|c|c|}
\hline \multirow{2}{*}{ Sample } & \multirow{2}{*}{ Atmospheric pressure } & \multirow{2}{*}{ Dosage of AEA (\%) } & \multirow{2}{*}{ Air content (\%) } & \multicolumn{4}{|c|}{ Compressive strength $(\mathrm{MPa})$} \\
\hline & & & & 7 days & 28 days & 90 days & 180 days \\
\hline $\mathrm{WH}$ & Tibet, $65.9 \mathrm{kPa}$ & 0.04 & 3.6 & 15.9 & 27.2 & 34.3 & 38.9 \\
\hline $\mathrm{XZ}$ & Hubei, $101.1 \mathrm{kPa}$ & 0.04 & 5.1 & 14.7 & 26.5 & 34.3 & 39.2 \\
\hline
\end{tabular}

TABLE 7: Frost resistance of concrete formed under different air pressures.

\begin{tabular}{|c|c|c|c|c|c|c|c|c|c|}
\hline \multirow{3}{*}{ Sample } & \multirow{3}{*}{ Atmospheric pressure } & \multirow{3}{*}{ AEA dosage (\%) } & \multirow{3}{*}{ Air content (\%) } & \multicolumn{6}{|c|}{ Frost resistance of 28 days } \\
\hline & & & & \multicolumn{3}{|c|}{$\begin{array}{c}\text { Relative dynamic } \\
\text { elasticity modulus (\%) }\end{array}$} & \multicolumn{3}{|c|}{ Loss of mass (\%) } \\
\hline & & & & $P_{50}$ & $P_{100}$ & $P_{150}$ & $W_{50}$ & $W_{100}$ & $W_{150}$ \\
\hline $\mathrm{WH}$ & Tibet, $65.9 \mathrm{kPa}$ & 0.04 & 3.6 & 90 & 86 & 78 & 0.4 & 1.2 & 2.7 \\
\hline $\mathrm{XZ}$ & Hubei, $101.1 \mathrm{kPa}$ & 0.04 & 5.1 & 93 & 90 & 84 & 0 & 0.3 & 1.0 \\
\hline
\end{tabular}

not sufficient to introduce bubbles in concrete and the bubbles easily escape from the concrete

3.3. Concrete Compressive Strength. Table 6 shows that the concrete compressive strength increases with the developing curing age. The air content of concrete mixing in Wuhan was higher $1.5 \%$ than that of the concrete mixing in Tibet. However, the compressive strength of these has no much difference. The 180-day compressive strength of concrete mixing in Wuhan is even slightly higher.

The concrete compressive strength generally decreases with the increasing air content value. The air content increases $1.3 \%, 2.9 \%$, and $4.7 \%$ for the corresponding decreasing compressive strength of $4.7 \%, 14.3 \%$, and $30.9 \%$, respectively [10]. The air content of concrete induced by the different ambient air pressures has slight effect on compressive strength. Thus, the air content of concrete is not the only parameter affecting compressive strength.

3.4. Concrete Frost Resistance Performance. Table 7 shows the test results of frost resistance of concrete formed under different ambient pressures. The CT scanning section of the specimen after 150 freeze-thaw cycles is shown in Figure 3. The results show that with the increase of freeze-thaw cycles, the macroscopic properties of concrete gradually deteriorate, the relative dynamic modulus decreases, and the loss of mass increases. After 150 freeze-thaw cycles, concrete specimens in Hubei have higher relative modulus of elasticity and less loss of mass so that the frost resistance is better than that of the concrete specimen in Tibet.

The meso- and microstructures of concrete reflect indirectly the macroscopic performance indexes. Aggregate, paste, the mesodistribution of pore structure, and the development of cracks after freeze-thaw damage can be shown by CT scanning [11]. In Figure 3, the density of the aggregate is hoar, the density of mortar is gray, and the lowest brightness spots are pores and cracks. Under the action of freeze-thaw cycles, the combined effect of ice expansion pressure and seepage pressure on the pore water of concrete pore will lead to the denudation failure from surface to interior [12]. There are uneven pores and some defects in the two groups of concrete specimens and more defects in the concrete of Tibet, especially, in the interface area around the aggregate. After freeze-thaw cycle damage, the specimens of Hubei are broken at the edge of concrete but there are obvious microcracks inside and outside the concrete in Tibet and some small cracks have been connected into larger defects.

3.5. Microstructure of Hardened Paste. Figure 4 shows the volume differential curve of the cumulative mercury content of hardened paste before and after freeze-thaw cycles. The pore structure results and pore size distribution of hardened paste are shown in Table 8 and Figure 5. The development of curve can roughly reflect the pore size distribution, in which the peak is the most probable pore size, which is the one with the highest probability. The more the peak to the left is, the larger the most probable pore size of the sample is. Zhongwei and Huizhen [13] suggested that the pore size in concrete can be divided into four levels, that is, $<20 \mathrm{~nm}$ (harmless pore), $20 \mathrm{~nm} \sim 100 \mathrm{~nm}$ (less harmful pore), $100 \mathrm{~nm} \sim 200 \mathrm{~nm}$ (harmful pore), and $>200 \mathrm{~nm}$ (more harmful pore). Strength and impermeability of concrete can be enhanced by increasing pores smaller than $50 \mathrm{~nm}$ and reducing pores larger than $100 \mathrm{~nm}$.

The two groups of reference pastes (WH and $\mathrm{XZ}$ ) under the different atmospheric pressures have the comparable, most probable pore size, but the peak of WH pastes is higher. The total porosity of hardened cement paste is $19.9 \%$ and $17.3 \%$ in Hubei and Tibet, respectively. However, the pore size of cement paste in Hubei is mainly concentrated $<100 \mathrm{~nm}$ (accounting for 93\%), most of them were less harmful and harmless pores, and the harmful pores are only $7.0 \%$. The uniformity of pore size distribution is relatively poor in Tibet's concrete, and the harmful pores larger than $100 \mathrm{~nm}$ are as high as $23.0 \%$.

Most probable aperture in the hardened paste increases, and the peak in the curve shifts to the left after 150 times of freeze-thaw cycle. The total porosity of specimens is increased; especially, the pores above $50 \mathrm{~nm}$ in size. In general, freeze-thaw cycles lead to increased harmful pores in paste. On the other hand, the deterioration process of hardened 

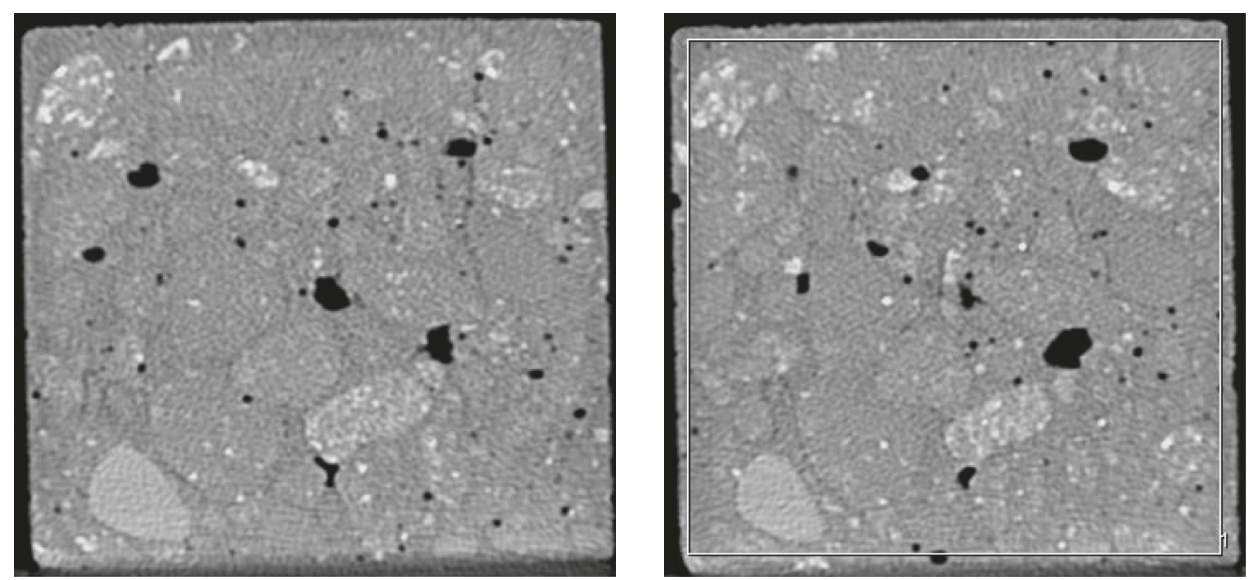

(a)
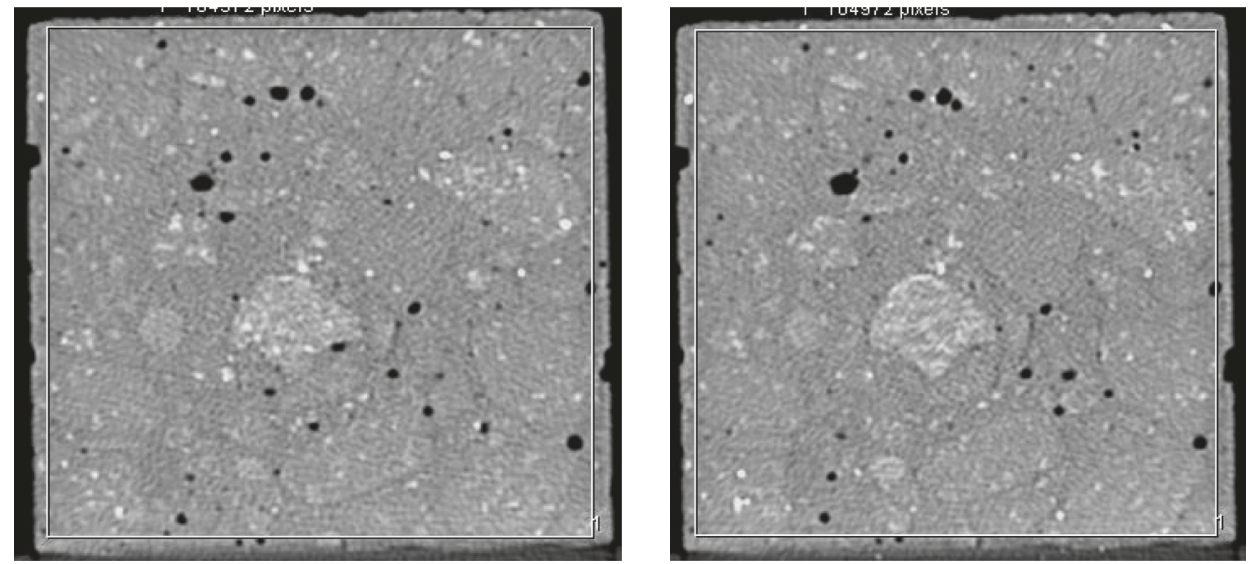

(b)

FIgURE 3: CT scanning diagram of the concrete section after 150 freeze-thaw cycles. (a) Sample of XZ. (b) Sample of WH.

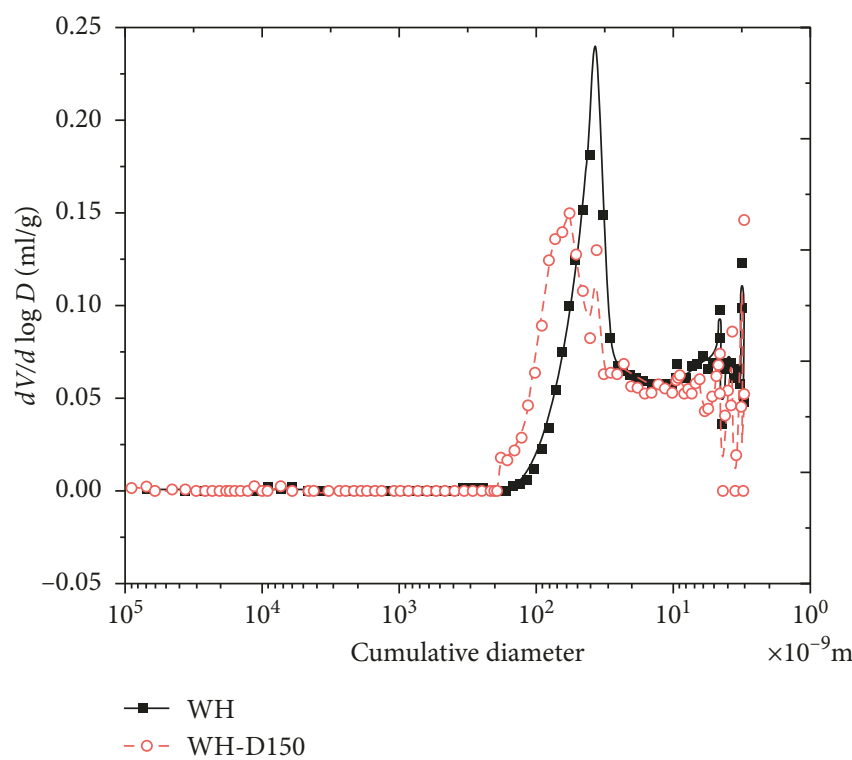

(a)

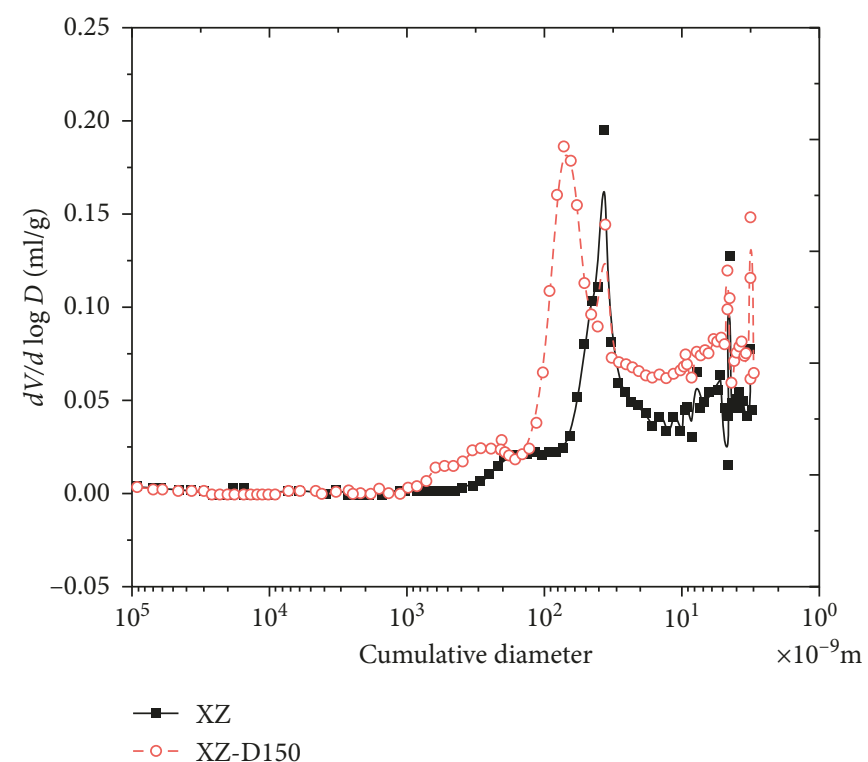

(b)

FiguRe 4: Cumulative differential curve of mercury content in hardened paste before and after freeze-thaw cycles. (a) Forming in Hubei. (b) Forming in Tibet. 
TABle 8: Pore structure of hardened paste.

\begin{tabular}{|c|c|c|c|c|c|c|c|c|c|}
\hline \multirow{2}{*}{ Sample } & \multirow{2}{*}{ Porosity (\%) } & \multicolumn{6}{|c|}{ Distribution of pore size (\%) } & \multirow{2}{*}{$<100 \mathrm{~nm}$} & \multirow{2}{*}{$\geq 100 \mathrm{~nm}$} \\
\hline & & $<5 \mathrm{~nm}$ & $5 \sim 20 \mathrm{~nm}$ & $20 \sim 50 \mathrm{~nm}$ & $50 \sim 100 \mathrm{~nm}$ & $100 \sim 200 \mathrm{~nm}$ & $>200 \mathrm{~nm}$ & & \\
\hline WH & 19.9 & 11.8 & 27.3 & 38.6 & 15.3 & 1.0 & 6.0 & 93.0 & 7.0 \\
\hline WH-D150 & 20.5 & 7.8 & 22.6 & 22.3 & 23.0 & 6.7 & 17.6 & 75.7 & 24.3 \\
\hline $\mathrm{XZ}$ & 17.3 & 9.2 & 25.4 & 31.8 & 10.6 & 5.8 & 17.2 & 77.0 & 23.0 \\
\hline XZ-D150 & 32.2 & 9.4 & 20.7 & 16.9 & 22.6 & 4.8 & 25.6 & 69.6 & 30.4 \\
\hline
\end{tabular}

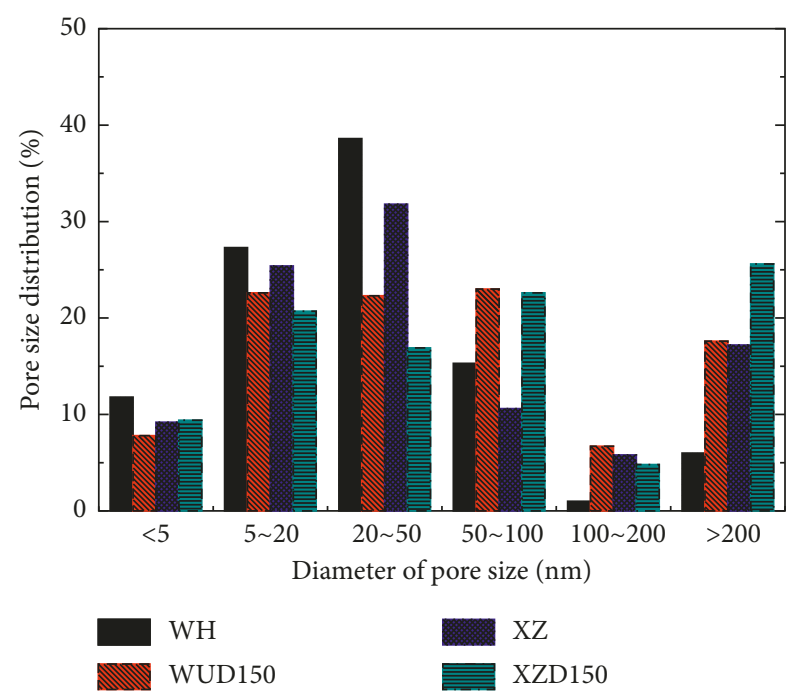

Figure 5: Pore size distribution of hardened paste.

paste in Tibet is faster and the final porosity is $32.2 \%$ (for $<100 \mathrm{~nm}$ less harmful or harmless pores $69.6 \%$ and $>100 \mathrm{~nm}$ harmful pores $30.4 \%$ ), which is higher than $20.5 \%$ of Hubei.

Therefore, the freeze-thaw cycle process increases the porosity of the cement paste, especially, the increase of less harmful and harmful holes. The concrete formed at low pressure in Tibet is more vulnerable to freeze-thaw damage, and the sensitivity of air pressure to the frost resistance is more than the mechanical properties which are in agreement with the test results.

3.6. Discussion of Mechanism. The adsorption of gas on the liquid surface and the solubility in liquid will decrease with the increase of atmospheric pressure. This will lead to the increase of the surface tension of AEA. The change of surface tension of AEA directly affects the size of pores. According to the Young-Laplace equation, the relationship between surface tension and bubble size is as follows:

$$
P=\frac{2 \sigma}{R}
$$

where $\sigma(\mathrm{mN} / \mathrm{m})$ is the surface tension and $R(\mu \mathrm{m})$ is the bubble radius.

According to (2), the bubble radius of different AEAs at different atmospheric pressures can be calculated, and the results are shown in Table 9. It is known that $R$ increases with the increase of $\sigma$, when $P$ is kept constant. When $P$ decreases, $\sigma$ increases and $R$ also increases. For example, when the surface tension of AEA is more at Tibet, it has strong endurance to the contraction of liquid molecules and can maintain a larger bubble radius, but the bubble wall may be thinner and easy to break. Hence, the stability is slightly worse.

It was shown [14] that bubble formation and bubble properties are related to gravity acceleration, liquid density, capillary radius, and so on. Therefore, compared with the low-altitude area, the internal pore radius of the concrete in the higher altitude area is larger. At the same site, the summer air pressure is higher than that in winter, so the air bubbles inside the concrete made in winter are much larger than those in summer. The atmospheric pressure affects the quality characteristics of AEA solution and air entraining effect, thus affecting the air content of fresh concrete and hardened paste pore structure. This shows that different pressures lead to differences in the macroscopic mechanics and frost resistance of concrete for the same ratio.

Therefore, in winter, the frost resistance durability of concrete at high-altitude area can be guaranteed through optimize the variety of AEA, appropriately increase the amount of AEA and improve the internal pore structure of concrete.

\section{Conclusions}

(1) When the ambient pressure is reduced from $101.1 \mathrm{kPa}$ to $57.2 \mathrm{kPa}$, the surface tension of two kinds of AEAs is increased by $118 \%$ and $114 \%$ and the foaming ability is decreased. The AEA A has strong foaming ability and good foam stability, and it is more suitable for air entraining concrete in low-pressure environment.

(2) Air content of fresh concrete in the Tibet area is lower than that of in the Hubei area from 30\% to $47 \%$. When the dosage of AEA is more, the gap is more. When the difference of air content is $1.4 \%$, the compressive strength of concrete is very close in two regions and the frost resistance of concrete affected by the pressure is more sensitive.

(3) The frost resistance of concrete formed at low air pressure is poor. As is shown in the CT diagram, there are obvious microcracks in the specimen except the edge damage, and some cracks connect into larger defects after freeze-thaw damage. The results of mercury injection show that the construction of cement paste becomes loose and the porosity and harmful pore ratio increase with the freeze-thaw process.

(4) The atmospheric pressure affects the air entraining effect of AEA solution which also affects the macroscopic properties of concrete and porous structure. 
TABLE 9: Calculated results of bubble radius of AEA.

\begin{tabular}{|c|c|c|c|c|c|}
\hline \multirow[t]{2}{*}{ Location } & \multirow[t]{2}{*}{ Atmospheric pressure $(\mathrm{kPa})$} & \multicolumn{2}{|c|}{$\begin{array}{l}\text { Surface tension } \sigma \\
\quad\left(\mathrm{mN} \cdot \mathrm{m}^{-1}\right)\end{array}$} & \multicolumn{2}{|c|}{ Bubble radius $R(\mu \mathrm{m})$} \\
\hline & & AEA A & AEA B & AEA A & AEA B \\
\hline Wuhan of Hubei & 100 & 29.4 & 31.9 & 58.8 & 63.8 \\
\hline Shannan of Tibet & 66 & 32.9 & 34.2 & 99.7 & 103.6 \\
\hline Naqu of Tibet & 57 & 34.6 & 36.3 & 121.4 & 127.4 \\
\hline
\end{tabular}

In order to ensure the frost resistance of concrete in high-altitude area, the internal pore structure of concrete should be improved by optimizing variety and dosage of AEA.

\section{Conflicts of Interest}

The authors declare that they have no conflicts of interest regarding the publication of this paper.

\section{Acknowledgments}

The work described in this paper was supported by the National Natural Science Foundation of China (nos. 51479011, 51779019, and 51778003) and the Central Non-Profit Scientific Research Fund for Institutes (no. CKSF2017052/CL)

\section{References}

[1] S. H. Zhou, Z. Q. Wang, J. Z. Li, and J. J. Yan, "Climatic characteristics of Tibet and its influence on durability of concrete," Water Power, vol. 38, no. 6, pp. 44-47, 2012.

[2] L. Du and K. J. Folliard, "Mechanisms of air entrainment in concrete," Cement and Concrete Research, vol. 35, no. 8, pp. 1463-1471, 2005.

[3] G. Fagerlund, "Air-pore instability and its effect on the concrete properties,” Nordic Concrete Research, vol. 9, pp. 34-52, 1990.

[4] R. C. Mielenz, V. E. Wolkodoff, J. E. Backstrom, and H. L. Flack, "Origin, evolution and effects of the air void system in concrete. Part 1-entrained air in unhardened concrete," ACI Structural Journal, vol. 55, pp. 95-121, 1958.

[5] M. T. Ley, R. Chancey, M. C. G. Juenger et al., "The physical and chemical characteristics of the shell of air-entrained bubbles in cement paste," Cement and Concrete Research, vol. 39, no. 5, pp. 417-425, 2009.

[6] C. H. Zhu, Y. J. Xie, Y. Zhang et al., "The effect of air pressure of environment on concrete's air-containing," Concrete, vol. 4, pp. 9-10, 2004.

[7] X. Li and Z. Fu, "Effect of low-pressure of environment on air content and bubble stability of concrete," Journal of the Chinese Ceramic Society, vol. 43, no. 8, pp. 1076-1082, 2015.

[8] B. Ding, J. P. Liu, and J. Z. Liu, "Studies on foam stabilization mechanism of air-entraining agent and improvement of freeze-thaw durability of concrete," Concrete, vol. 11, 2006.

[9] X. Li, Z. Fu, Z. Luo et al., "Effect of low-pressure in plateau environment on air content of fresh concrete," Journal of Southeast University, vol. 44, no. 5, pp. 1046-1051, 2014.

[10] Q. S. Wang, Q. C. Wang, K. Zhang et al., "Analysis of pore structure and frost resistance of concrete with different air content," Bulletin of the Chinese Ceramic Society, vol. 34, no. 1, pp. 30-35, 2015.

[11] T. Suzuki, T. Shiotani, and M. Ohtsu, "Evaluation of cracking damage in freeze-thawed concrete using acoustic emission and X-ray CT image," Construction and Building Materials, vol. 136, pp. 619-626, 2017.

[12] J. J. Valenza II and G. W. Scherer, "A review of salt scaling: I. phenomenology," Cement and Concrete Research, vol. 37, no. 7, pp. 1007-1021, 2007.

[13] W. Zhongwei and L. Huizhen, High Performance Concrete, China Railway Press, Beijing, China, 1999.

[14] J. K. Chen, Principle and Application of Concrete Admixture, China Technology Press, Beijing, China, 1997. 


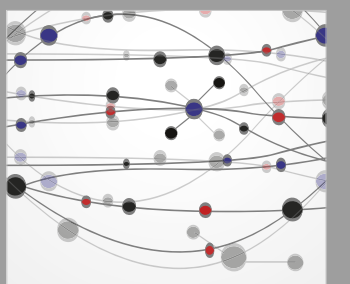

The Scientific World Journal
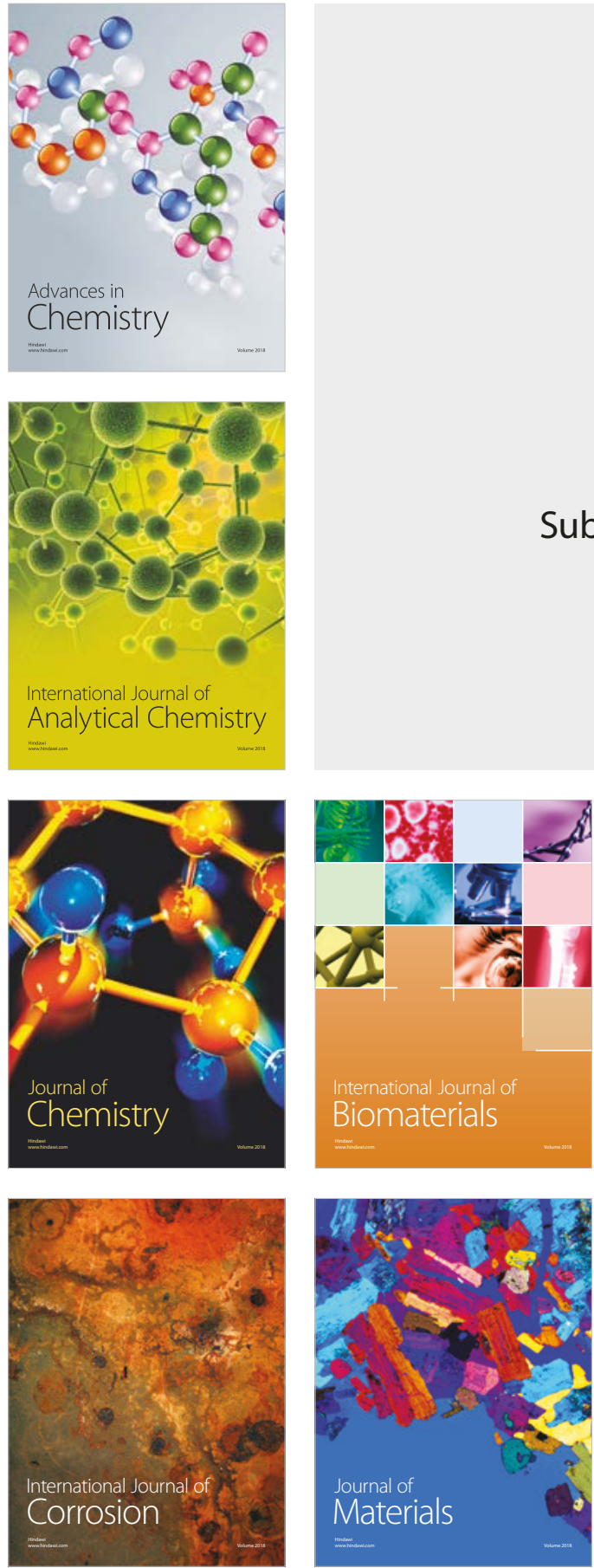

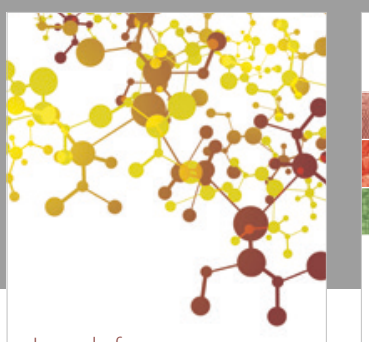

Journal of

Applied Chemistry
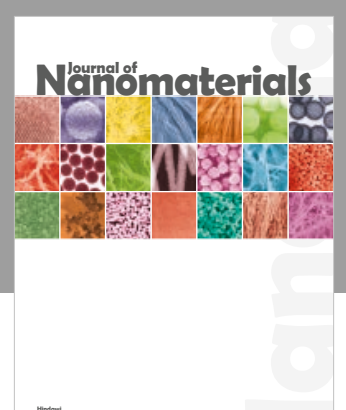

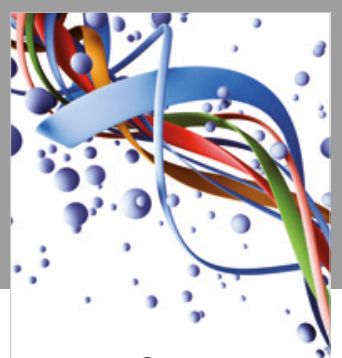

Scientifica

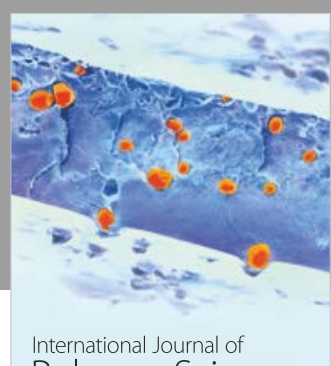

Polymer Science

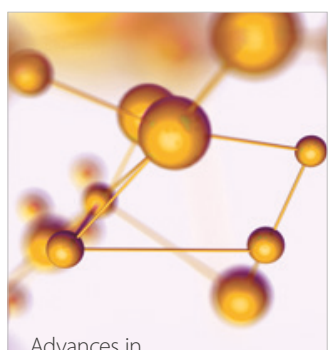

Physical Chemistry
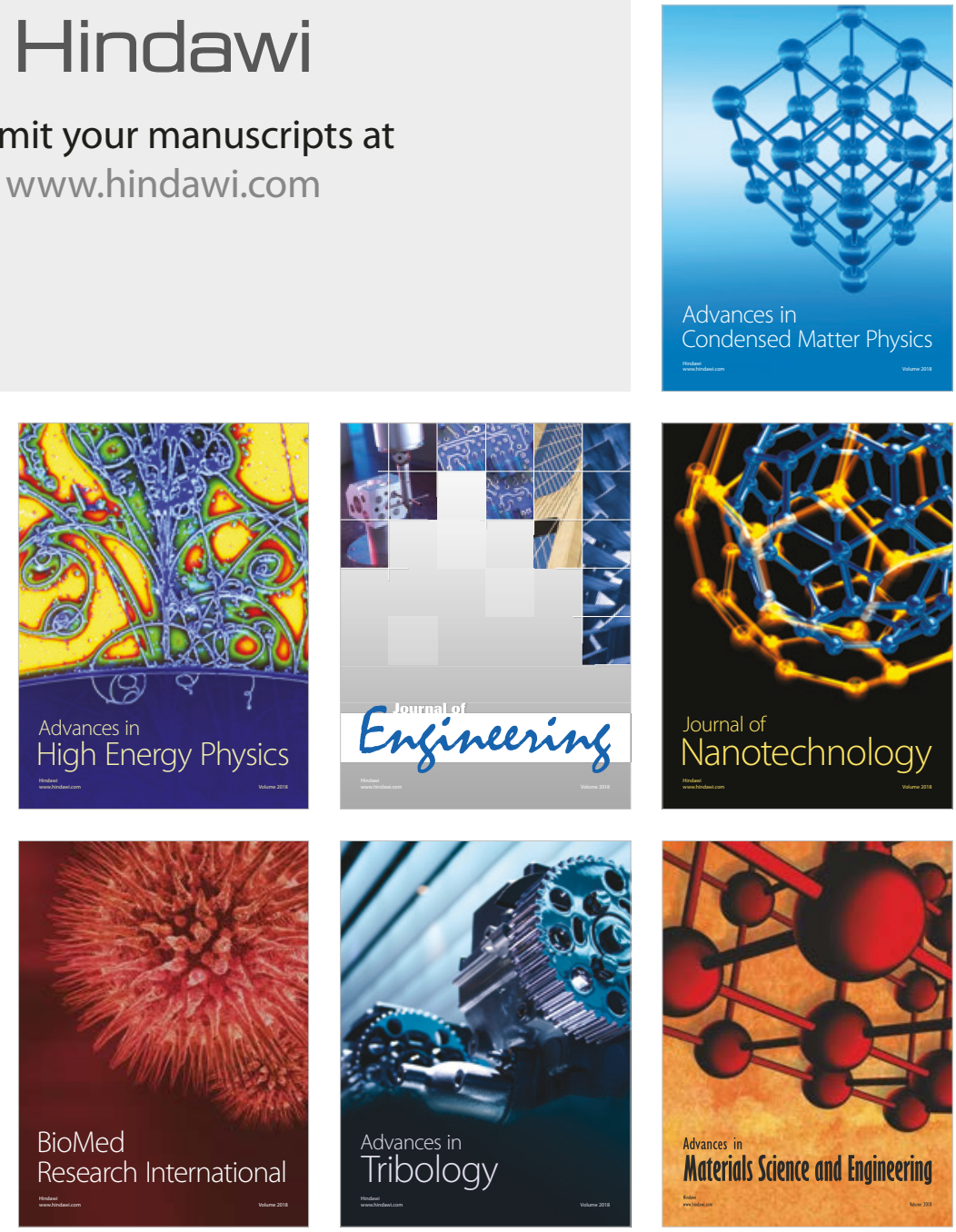